\title{
Variations in the prevalence across countries of chronic bronchitis and smoking habits in young adults
}

\author{
I. Cerveri*, S. Accordini", G. Verlato", A. Corsico*, M.C. Zoia*, L. Casali*, P. Burney", \\ R. de Marco", for the European Community Respiratory Health Survey (ECRHS) Study Group
}

Variations in the prevalence across countries of chronic bronchitis and smoking habits in young adults. I. Cerveri, S. Accordini, G. Verlato, A. Corsico, M. C. Zoia, L. Casali, P. Burney, R.de Marco, for the European Community Respiratory Health Survey (ECRHS) Study Group. (C) ERS Journals Ltd 2001.

ABSTRACT: The present work aims to assess the international variation in the prevalence of chronic bronchitis and its main risk factor, smoking habits, in young adults of 35 centres from 16 countries.

Respiratory symptoms and pulmonary function were assessed in 17,966 subjects $(20-44 \mathrm{yrs})$, randomly selected from the general population, in the frame of the European Community Respiratory Health Survey.

The median prevalence of chronic bronchitis was $2.6 \%$, with wide variations across countries $(p<0.001 ; 0.7-9.7 \%)$. The prevalence of current smokers ranged $20.1-56.9 \%(p<0.001)$ with a median value of $40 \%$. Current smoking was the major risk factor for chronic bronchitis, especially in males. Its effect increased according to number of pack-yrs: in males, the odds ratio of chronic bronchitis was 3.51 (95\% confidence interval (CI) 2.31 -5.32) in 1-14 pack-yrs smokers and increased to $17.32(9.97-30.11)$ in $\geqslant 45$ pack-yrs smokers with respect to nonsmokers. Only $30 \%$ of the geographical variability in prevalence could be explained by differences in smoking habits, suggesting that other environmental and/or genetic factors may play an important role.

In conclusion, chronic bronchitis is a substantial health problem even in young adults. The impressive prevalence in current smokers in most countries highlights the need to improve the quality of prevention.

Eur Respir J 2001; 18: 85-92.

\begin{abstract}
*Institute of Respiratory Disease, IRCCS Policlinico S. Matteo, University of Pavia and ${ }^{\#}$ Unit of Epidemiology and Medical Statistics, University of Verona, Italy. "Dept of Public Health Sciences, King's College, Guy's Hospital, London, UK.
\end{abstract}

Correspondence: R. de Marco, Sezione di Epidemiologia e Statistica Medica, Istituti Biologici II, strada Le Grazie 8, 37134 Verona, Italy. Fax: 39045505357

Keywords: Chronic bronchitis
epidemiology
prevalence
risk factors
smoking
young adults

Received: October 52000 Accepted after revision February 17 2001

This study was partially supported by grants from the European Commission, the Italian Ministry of University and Scientific and Technological Research (MURST) and from the Veneto Region.
Knowledge of the prevalence of chronic bronchitis is still incomplete because of many methodological problems in epidemiological studies, above all imprecise and variable definitions of the disease. Frequently, in the past the terms "chronic bronchitis" and chronic obstructive pulmonary disease (COPD) have been used interchangeably; currently, the international guidelines give a precise definition for COPD that distinguishes it exactly from simple chronic bronchitis, but they do not clarify the natural relationship between the two diseases [1-3]. For this purpose more information on the younger population is required.

The prevalence of chronic bronchitis and the distribution of its major risk factor, cigarette smoking, seem to vary widely across countries. However, available data are not easily comparable.

The European Community Respiratory Health Survey (ECRHS) on the general population of young adults provided the opportunity to analyse data concerning chronic bronchitis, collected in western European and other industrialized countries
(35 centres from 13 European and three countries outside Europe) [4]. Results of an analysis of the ECRHS questionnaire and spirometry data are presented in order to assess the geographical distribution of the prevalence of chronic bronchitis and of its main risk factor, smoking habits, in young adults.

\section{Material and methods}

\section{Study design and subjects}

The full protocol for the ECRHS has been described previously [4]. Briefly, participating centres selected an area of at least 150,000 inhabitants, defined by pre-existing administrative boundaries, with an up-to-date sampling frame. In the first stage of the study, randomly selected samples of at least 1,500 people of each sex, aged $20-44$ yrs, were sent a screening questionnaire enquiring about respiratory symptoms, attacks of asthma, use of asthma 
medications and hay fever or nasal allergies. In the second stage of the study, a random sample of subjects who had completed the screening questionnaire were invited to come in for a set of clinical and functional tests, including a standardized clinical interview and assessment of lung function by spirometry.

For the purpose of the present analysis, all the subjects involved in stage 2 in 1991-1993 who answered the questions on chronic bronchitis and asthma during the clinical interview were considered. They were selected from 35 centres in 16 countries. As shown in table 1, 17,966 subjects were eligible for the analysis, yielding an overall response rate of $48.8 \%$ (range $12.1-100 \%)$; of these, $14,819(82.5 \%)$ had at least two technically satisfactory measurements of forced expiratory volume in one second (FEV1) and forced vital capacity (FVC). Women were more strongly represented in the overall study base $(51.9 \%$ versus $48.1 \%$ ), however, they were less likely to have reliable lung function tests $(79.4 \%$ versus $85.8 \%)$.

\section{Methods}

Subjects were classified as having chronic bronchitis if they reported having cough and phlegm from the chest usually in winter and on most days for as many as 3 months each year. Subjects fulfilling these criteria were not considered as cases if they also reported ever having been diagnosed as asthmatic by a family doctor. The questions used by ECRHS were those of the 1976 version of the British Medical Research Council Questionnaire [5].

Baseline FVC and FEV1 were measured in all subjects who agreed, following a standardized protocol [6]. Bronchial obstruction was defined as a FEV1/

Table 1. - Number of subjects randomly selected for the European Community Respiratory Health Survey (ECRHS)-stage 2 , number $(\%)$ of responders to questions on asthma and bronchitis, and number (\%) of subjects with at least two technically acceptable measurements of forced expiratory volume in one second (FEV 1 ) and forced vital capacity (FVC)

\begin{tabular}{|c|c|c|c|c|c|}
\hline \multirow[t]{2}{*}{ Center (Country) } & \multirow{2}{*}{$\begin{array}{l}\text { Subjects selected for } \\
\text { ECRHS-stage } 2 \\
\mathrm{n}\end{array}$} & \multicolumn{2}{|c|}{$\begin{array}{l}\text { Subjects filling } \\
\text { in the questionnaire }\end{array}$} & \multicolumn{2}{|c|}{$\begin{array}{l}\text { Subjects with reliable } \\
\text { FEV1 and FVC measurement }\end{array}$} \\
\hline & & $\mathrm{n}$ & $\% *$ & $\mathrm{n}$ & $\%^{\#}$ \\
\hline Antwerp South (Belgium) & 800 & 555 & 69.4 & 362 & 65.2 \\
\hline Antwerp City (Belgium) & 867 & 560 & 64.6 & 335 & 59.8 \\
\hline Aarhus (Denmark) & 652 & 363 & 55.7 & 290 & 79.9 \\
\hline Hamburg (Germany) & 3312 & 1251 & 37.8 & 1008 & 80.6 \\
\hline Erfurt (Germany) & 1076 & 721 & 67.0 & 629 & 87.2 \\
\hline Barcelona (Spain) & 534 & 393 & 73.6 & 207 & 52.7 \\
\hline Galdakao (Spain) & 576 & 486 & 84.4 & 386 & 79.4 \\
\hline Albacete (Spain) & 658 & 435 & 66.1 & 416 & 95.6 \\
\hline Oviedo (Spain) & 522 & 355 & 68.0 & 254 & 71.5 \\
\hline Huelva (Spain) & 478 & 271 & 56.7 & 249 & 91.9 \\
\hline Bordeaux (France) & 2936 & 539 & 18.4 & 429 & 79.6 \\
\hline Grenoble (France) & 1165 & 484 & 41.5 & 466 & 96.3 \\
\hline Montpellier (France) & 3736 & 451 & 12.1 & 442 & 98.0 \\
\hline Paris (France) & 3113 & 648 & 20.8 & 574 & 88.6 \\
\hline Dublin (Ireland) & 599 & 411 & 68.6 & 295 & 71.8 \\
\hline Pavia (Italy) & 816 & 284 & 34.8 & 235 & 82.7 \\
\hline Turin (Italy) & 518 & 243 & 46.9 & 208 & 85.6 \\
\hline Verona (Italy) & 504 & 354 & 70.2 & 316 & 89.3 \\
\hline Groningen (the Netherlands) & 599 & 425 & 71.0 & 406 & 95.5 \\
\hline Bergen-op-Zoom (the Netherlands) & 638 & 496 & 77.7 & 481 & 97.0 \\
\hline Geleen (the Netherlands) & 671 & 436 & 65.0 & 401 & 92.0 \\
\hline Cambridge (UK) & 527 & 274 & 52.0 & 218 & 79.6 \\
\hline Ipswich (UK) & 682 & 399 & 58.5 & 382 & 95.7 \\
\hline Norwich (UK) & 655 & 460 & 70.2 & 360 & 78.3 \\
\hline Reykjavik (Iceland) & 672 & 564 & 83.9 & 528 & 93.6 \\
\hline Bergen (Norway) & 969 & 969 & 100.0 & 881 & 90.9 \\
\hline Goteborg (Sweden) & 772 & 682 & 88.3 & 590 & 86.5 \\
\hline Umea (Sweden) & 611 & 551 & 90.2 & 465 & 84.4 \\
\hline Uppsala (Sweden) & 709 & 608 & 85.8 & 475 & 78.1 \\
\hline Basel (Switzerland) & 1210 & 844 & 69.8 & 748 & 88.6 \\
\hline Wellington (New Zealand) & 741 & 470 & 63.4 & 344 & 73.2 \\
\hline Christchurch (New Zealand) & 712 & 449 & 63.1 & 325 & 72.4 \\
\hline Hawkes Bay (New Zealand) & 549 & 314 & 57.2 & 189 & 60.2 \\
\hline Portland (USA) & 1604 & 553 & 34.5 & 373 & 67.5 \\
\hline Melbourne (Australia) & 1644 & 668 & 40.6 & 552 & 82.6 \\
\hline Total & 36827 & 17966 & 48.8 & 14819 & 82.5 \\
\hline
\end{tabular}

*: $\%$ are computed using people selected for random sample as reference; ${ }^{\#}: \%$ are computed using people filling in the questionnaire as reference. 
FVC ratio $<70 \%$ according to the American Thoracic Society [7]. This previous criterion was chosen because it was recently found to be the most accurate, with a good specificity with respect to presence/absence of chronic respiratory disease [8].

Subjects were classified according to smoking habits as current smokers, past smokers, nonsmokers. Subjects were considered smokers if they stated in the questionnaire that they were current smokers and had smoked $\geqslant 20$ packs of cigarettes or $360 \mathrm{~g}$ of tobacco in a lifetime or at least one cigarette per day or one cigar a week for $1 \mathrm{yr}$. Current smokers were classified into four subgroups according to pack-yrs. Subjects were considered past smokers if they had been smokers (as defined above) and had stopped smoking $>1$ month previously. All the other subjects were considered to be nonsmokers.

Other risk factors considered for the analysis were: self-reported serious respiratory infection before the age of $5 \mathrm{yrs}$, a history of occupational exposure to vapours, gas, dust or fumes, low socioeconomic status (as indicated by having completed full-time education before the age of $16 \mathrm{yrs}$ ).

\section{Analysis}

Data were summarized as prevalence rates $(\%)$ with 95\% confidence intervals (CI). Prevalence rates were compared between sexes and among centres using the Chi-squared test. The ecological correlation between rates (using each ECRHS centre as a unit) was computed using Pearson's correlation coefficient after normalization of prevalence by an angular transformation, which is the most suitable procedure for proportions [9].

When necessary, meta-analysis was performed using the Mantel-Haenszel method [10], which yielded a pooled odds ratio (OR). Pooled estimates were used when the Chi-squared test for homogeneity did not reveal different patterns in the various centres.

A multilevel logistic regression model [11] with subjects nested within ECRHS centres was used to assess the independent effect of explanatory variables (smoking habits, respiratory infections in childhood, occupational exposure and socioeconomic status) on the prevalence of chronic bronchitis. The model had a random intercept term at the level of the ECRHS centre and all predictors variables as fixed effects. The ORs were computed also adjusting for the effect of the percentage of responders to questions on asthma and bronchitis in each ECRHS centre. As age and packyrs were strongly correlated in our sample of young adults, the effect of age was studied using a multilevel logistic regression model with smoking habits recoded as current, past or no history of smoking, in order to avoid co-linearity [12].

\section{Results}

In the total sample of 17,966 subjects aged $20-44$ yrs, $580(3.2 \%)$ reported chronic bronchitis. The median prevalence was $2.6 \%$, ranging from $0.7 \%$

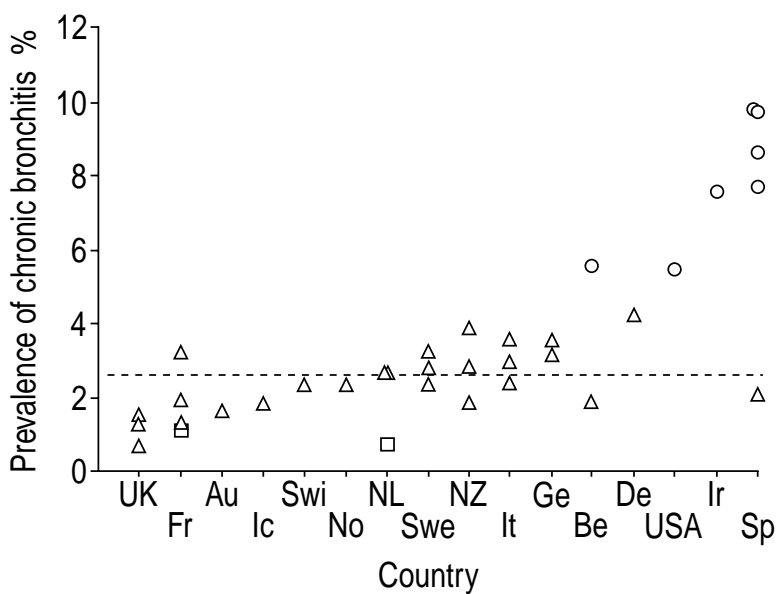

Fig. 1. - Prevalence of chronic bronchitis plotted by country and centre. Each symbol represents the value for one centre. Countries are ordered along the abscissa by increasing values of the median within each country. The dotted line indicates the median of the prevalences. Values significantly above or below the median for 35 centres are indicated. $\square$ : 95\% confidence interval (CI) below and excludes study median; $\triangle 95 \%$ CI includes study median; $\bigcirc: 95 \%$ CI above and excludes study median. UK: United Kingdom; Fr: France; Au: Australia; Ic: Iceland; Swi: Switzerland; No: Norway; NL: the Netherlands; Swe: Sweden; NZ: New Zealand; It: Italy; Ge: Germany; Be: Belgium; De: Denmark; USA: United States of America; Ir: Ireland; Sp: Spain.

(Geleen, the Netherlands) to 9.7\% (Albacete, Spain). As depicted in figure 1, the prevalence of chronic bronchitis varied widely across countries $(p<0.001)$. The UK and France had the lowest rates, while Spain, Ireland and the USA had the highest rates. A statistically significant within-country variation was observed in Spain $(\mathrm{p}<0.001)$, Belgium $(\mathrm{p}=0.002)$, France $(p=0.04)$ and the Netherlands $(p=0.04)$.

The rates reported in females were significantly lower than those in males $(2.8 \%$ versus $3.7 \%$; $\mathrm{p}<0.001)$, and this difference between sexes remained constant across centres (Chi-squared for homogeneity: $\mathrm{p}=0.6)$. The pooled estimate of the OR for females versus males was 0.72 (95\% CI: $0.61-0.85)$.

Average $\mathrm{FEV} 1 / \mathrm{FVC}$ ratio and average $\mathrm{FEV} 1 \%$ pred were significantly lower when chronic bronchitis was present, both in males $(79.1 \%$ in chronic bronchitic subjects versus $81.5 \%$ in the other subjects, $\mathrm{p}<0.001$, and $99.9 \%$ versus $104.7 \%, \mathrm{p}<0.001$, respectively) and in females $(82.1 \%$ versus $83.7 \%, \mathrm{p}=0.001$, and $103.6 \%$ versus $106.3 \%, \mathrm{p}=0.004$, respectively).

Bronchial obstruction was significantly more common in subjects with chronic bronchitis $(8.4 \%)$ than in the other subjects $(4.3 \%)(\mathrm{p}<0.001)$, and among chronic bronchitic individuals it was significantly more frequent in males than in females $(10.9 \%$ versus $4.9 \% ; \mathrm{p}=0.03)$.

Out of the 17,802 responders for whom there was valid information on smoking habits, 6,562 (36.9\%) reported that they were current smokers, while 3,709 subjects $(20.8 \%)$ had stopped smoking. Among smokers, $759(11.6 \%)$ reported having smoked $\geqslant 30$ pack-yrs. The prevalence of current smokers varied widely across countries $(\mathrm{p}<0.001)$, ranging from $20.1 \%$ (Portland, USA) to $56.9 \%$ (Oviedo, Spain), 


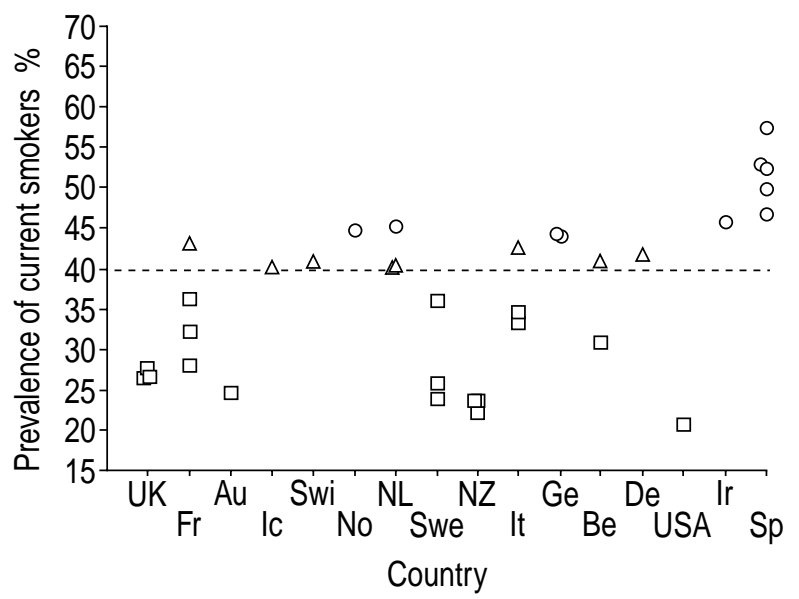

Fig. 2. - Prevalence of current smokers plotted by country and centre. Each symbol represents the value for one centre. Countries are ordered along the abscissa by increasing values of the median of the prevalences of chronic bronchitis within each country. The dotted line indicates the median of the prevalences of current smokers. Values significantly above or below the median for 35 centres are indicated. $\square$ : 95\% confidence interval (CI) below and excludes study median; $\triangle 95 \% \mathrm{CI}$ includes study median; $\bigcirc: 95 \%$ $\mathrm{CI}$ above and excludes study median. UK: United Kingdom; Fr: France; Au: Australia; Ic: Iceland; Swi: Switzerland; No: Norway; NL: the Netherlands; Swe: Sweden; NZ: New Zealand; It: Italy; Ge: Germany; Be: Belgium; De: Denmark; USA: United States of America; Ir: Ireland; Sp: Spain.

with a median value of $40 \%$ (fig. 2). In general, the centres with the lowest rates of chronic bronchitis also had a low prevalence of current smokers (UK, France and Australia) and vice versa (Spain and Ireland). An exception was the centre in the USA which, despite the lowest prevalence of current smokers, had one of the highest rates of chronic bronchitis. The ecological correlation coefficient between the prevalence of current smokers and the prevalence of chronic bronchitis was $0.55(p=0.001)$, suggesting that approximately one third of the geographic variability in chronic bronchitis prevalence could be due to differences in smoking habits. Females smoked less than males $(34.3 \%$ versus $39.6 \% ; \mathrm{p}<0.001)$, while the percentages of past smokers were almost identical in both sexes $(20.7 \%$ versus $21.0 \% ; \mathrm{p}=0.67)$ (table 2$)$. This sex-related pattern varied across centres (Chisquared for homogeneity; $p<0.001)$. While in most centres the prevalence of current smokers was higher in males, it was higher in females in some northern European countries (Sweden, Denmark, Ireland) and in New Zealand.

As shown in figure 3, FEV1 \% pred declined progressively as the number of pack-yrs increased in both sexes: in males it decreased from $105.6 \%$ in nonsmokers up to $97.0 \%$ in very heavy smokers $(\geqslant 45$ pack-yrs), and in females from $106.5 \%$ to $98.4 \%$. FEV1 \% predicted was usually lower in chronic bronchitic subjects.

Both males and females with chronic bronchitis included a larger proportion of current smokers, in particular heavy smokers ( $\geqslant 30$ pack-yrs), and a lower proportion of people who had stopped smoking $(\mathrm{p}<0.001)$ compared to people without chronic bronchitis (table 3). The percentages of current smokers and heavy smokers were particularly high in the 41 chronic bronchitic subjects with bronchial obstruction $(82.9 \%$ and $46.3 \%)$.

Current smoking was the major risk factor for chronic bronchitis both in males and females (table 4). The effect of smoking was slightly more pronounced in males than in females and increased as a function of pack-yrs: with respect to male nonsmokers, the OR of chronic bronchitis was 3.51 (95\% CI: $2.31-5.32)$ in male light smokers $(1-14$ pack-yrs) and increased to $17.32(9.97-30.11)$ in very heavy smokers $(\geqslant 45$ packyrs). In females, the corresponding figures were lower, as the OR of chronic bronchitis was $3.06(2.13-4.40)$ in light smokers and $10.63(4.69-24.13)$ in very heavy smokers. Occupational exposure was a significant risk factor in both sexes, while low socioeconomic status

Table 2. - Prevalence of current smokers and past smokers by sex and country in people attending the European Community Respiratory Health Survey (ECRHS)-stage 2

\begin{tabular}{|c|c|c|c|c|}
\hline \multirow[t]{2}{*}{ Country } & \multicolumn{2}{|c|}{ Current smokers $\%$} & \multicolumn{2}{|c|}{ Past smokers \% } \\
\hline & Males & Females & Males & Females \\
\hline Belgium & $40.5(36.1-45.0)$ & $31.5(27.9-35.3)$ & $18.7(15.4-22.5)$ & $24.0(20.7-27.5)$ \\
\hline Denmark & $40.8(32.9-49.0)$ & $41.6(34.7-48.7)$ & $18.4(12.6-25.5)$ & $12.4(8.2-17.7)$ \\
\hline Germany & $47.8(44.7-50.9)$ & $39.7(36.6-42.9)$ & $22.8(20.2-25.5)$ & $22.5(19.9-25.3)$ \\
\hline Spain & $58.6(55.3-61.7)$ & $44.3(41.2-47.4)$ & $14.1(12.0-16.5)$ & $14.5(12.4-16.9)$ \\
\hline France & $38.3(35.3-41.3)$ & $32.0(29.2-34.9)$ & $24.6(22.1-27.4)$ & $24.1(21.6-26.8)$ \\
\hline Ireland & $44.2(37.3-51.2)$ & $46.5(39.5-53.7)$ & $18.4(13.4-24.4)$ & $13.9(9.4-19.4)$ \\
\hline Italy & $42.8(38.1-47.6)$ & $30.1(25.8-34.6)$ & $20.0(16.4-24.1)$ & $18.6(15.0-22.5)$ \\
\hline The Netherlands & $44.3(40.4-48.2)$ & $39.1(35.4-42.9)$ & $20.0(17.0-23.3)$ & $23.1(19.9-26.4)$ \\
\hline UK & $28.3(24.3-32.5)$ & $25.9(22.5-29.5)$ & $24.6(20.8-28.6)$ & $18.4(15.5-21.6)$ \\
\hline Iceland & $42.0(36.1-48.1)$ & $38.3(32.7-44.1)$ & $25.2(20.2-30.8)$ & $20.3(15.9-25.4)$ \\
\hline Norway & $46.1(41.6-50.7)$ & $43.3(38.8-47.9)$ & $13.5(10.6-16.8)$ & $17.2(13.9-20.8)$ \\
\hline Sweden & $26.2(23.3-29.2)$ & $31.0(28.1-34.1)$ & $23.6(20.9-26.5)$ & $21.7(19.1-24.5)$ \\
\hline Switzerland & $41.2(36.5-46.1)$ & $40.2(35.5-45.1)$ & $19.2(15.5-23.3)$ & $17.3(13.8-21.3)$ \\
\hline New Zealand & $21.8(18.4-25.6)$ & $23.7(20.4-27.4)$ & $24.3(20.7-28.1)$ & $24.2(20.9-27.9)$ \\
\hline USA & $23.5(18.1-29.7)$ & $17.8(13.8-22.3)$ & $19.9(14.9-25.8)$ & $21.7(17.4-26.5)$ \\
\hline Australia & $26.8(22.0-32.0)$ & $22.3(18.0-27.0)$ & $25.2(20.6-30.4)$ & $27.7(23.1-32.8)$ \\
\hline
\end{tabular}

Data are presented as prevalence rates (\%) with $95 \%$ confidence interval in parentheses. 

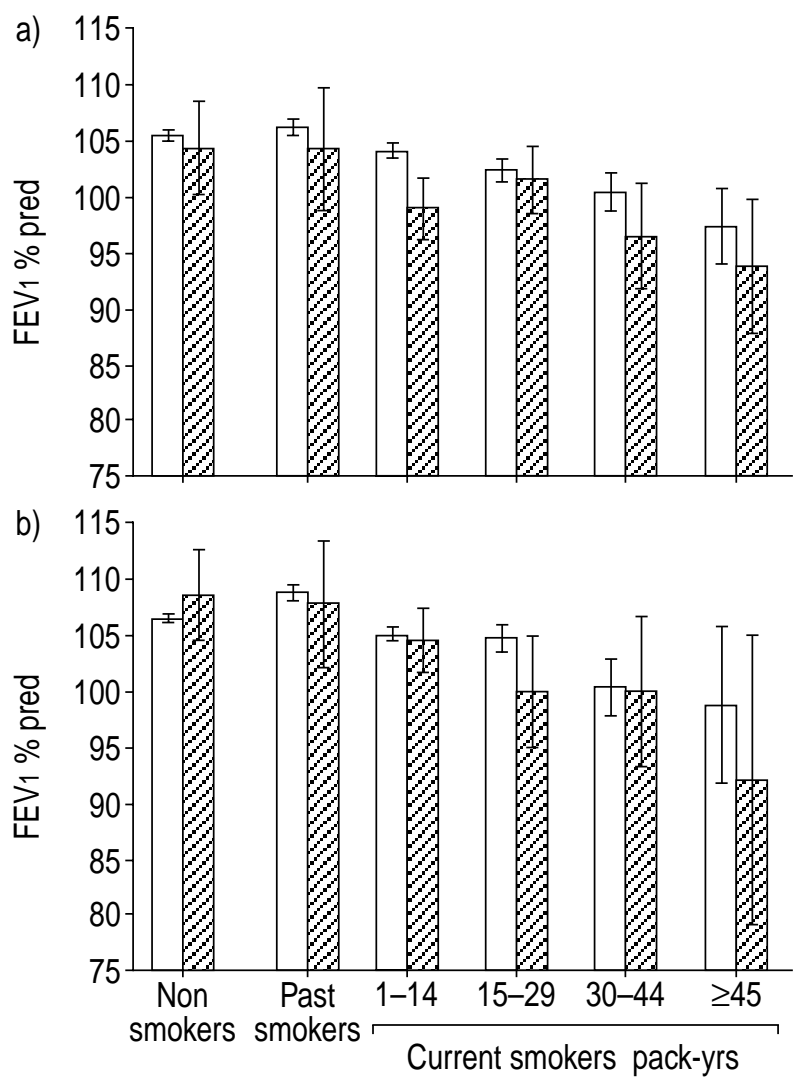

Fig. 3. - Forced expiratory volume in one second (FEV1) \% predicted in a) males and b) females, plotted according to chronic bronchitis and smoking habits. $\square$ : without chronic bronchitis; $\mathbb{Z}$ : with chronic bronchitis.

influenced the risk only in males. Past smoking and childhood respiratory infections did not play significant roles in the development of chronic bronchitis. No significant interaction emerged between smoking habits and any other explanatory variable.

In the sample, no effect of age on chronic bronchitis was detected, even when smoking habits were recoded as present, past or no history of smoking. With respect to the $20-24$ yrs class, the OR was $1.03(0.77-1.37)$ in people aged $25-34 \mathrm{yrs}$ and $1.10(0.83-1.47)$ in people aged $35-44$.

In an ecological regression model, current smoking, occupational exposure and socioeconomic status accounted for $44 \%$ of the variability of the prevalence of chronic bronchitis across the countries.

\section{Discussion}

The main findings of the present analysis of the ECRHS international database are: 1) chronic bronchitis is a substantial health problem even in young adults in almost all countries; 2) there is a documented, wide variation in chronic bronchitis prevalence both across and within countries, which is only partially explained by different patterns in smoking habits; and 3) despite a huge effort by international and local health agencies in preventing and reducing smoking, the proportion of current smokers among young adults is still impressively high $(>30 \%)$ in most countries. Exceptions are the USA, New Zealand and Australia, where the proportion of past smokers exceeds the proportion of current smokers, perhaps as a result of successful antismoking campaigns.

There are many epidemiological studies reporting chronic bronchitis and/or COPD data in adults and elderly people [13-15]. The peculiarity of the present study is that it focuses attention on the younger population, referring to almost 18,000 subjects aged $20-44$ yrs. The disease is most often diagnosed in the fifth or sixth decade, but there is accumulating evidence that it starts much earlier in life [14, 16]. The presented data are consistent with this evidence, as $>50 \%$ of the ECRHS centres had a prevalence $>2.6 \%$, while only a small percentage of these affected individuals had bronchial obstruction. Even if the lung function values were significantly lower in subjects with chronic bronchitis, on average they were within the normal range.

Probably, at least in some subjects with chronic bronchitis, particularly the nonsmokers, different pathogeneses could be involved, such as chronic rhinosinusitis or bronchiectasis. These patients could

Table 3. - Distribution of smoking habits in both sexes by the presence of chronic bronchitis

\begin{tabular}{|c|c|c|c|c|c|c|}
\hline \multirow[t]{2}{*}{ Smoking habits } & \multicolumn{2}{|c|}{ Males*** } & \multicolumn{2}{|c|}{ Females*** } & \multicolumn{2}{|c|}{ Total*** } \\
\hline & $\begin{array}{l}\text { With chronic } \\
\text { bronchitis }\end{array}$ & $\begin{array}{l}\text { Without chronic } \\
\text { bronchitis }\end{array}$ & $\begin{array}{l}\text { With chronic } \\
\text { bronchitis }\end{array}$ & $\begin{array}{l}\text { Without chronic } \\
\text { bronchitis }\end{array}$ & $\begin{array}{l}\text { With chronic } \\
\text { bronchitis }\end{array}$ & $\begin{array}{l}\text { Without chronic } \\
\text { bronchitis }\end{array}$ \\
\hline Nonsmokers & $43(13.4)$ & 3332 (40.4) & $55(21.6)$ & $4101(45.7)$ & $98(17.0)$ & $7433(43.1)$ \\
\hline Past smokers & $30(9.3)$ & $1767(21.4$ & $26(10.2)$ & $1886(21.0)$ & $56(9.7)$ & $3653(21.2)$ \\
\hline Current smokers & $248(77.3)$ & $3148(38.2)$ & $174(68.2)$ & $2992(33.3)$ & $422(73.3)$ & $6140(35.6)$ \\
\hline $1-14$ pack-yrs & $71(22.1)$ & 1537 (18.6) & $80(31.4)$ & $1906(21.2)$ & $151(26.2)$ & $3443(20.0)$ \\
\hline $15-29$ pack-yrs & $81(25.2)$ & 941 (11.4) & $52(20.4)$ & $753(8.4)$ & $133(23.1)$ & $1694(9.8)$ \\
\hline $30-44$ pack-yrs & $48(15.0)$ & $297(3.6)$ & $24(9.4)$ & 175 (1.9) & $72(12.5)$ & $472(2.7)$ \\
\hline$\geqslant 45$ pack-yrs & $33(10.3)$ & $120(1.5)$ & $9(3.5)$ & $53(0.6)$ & $42(7.3)$ & $173(1.0)$ \\
\hline Unknown & $15(4.7)$ & $253(3.1)$ & $9(3.5)$ & $105(1.2)$ & $24(4.2)$ & $358(2.1)$ \\
\hline Total & 321 & 8247 & 255 & 8979 & 576 & 17226 \\
\hline
\end{tabular}

Data are presented as $\mathrm{n}(\%)$. Some subjects $(\mathrm{n}=164)$ did not answer questions on smoking habits. $* * *: p<0.001$, the distribution of smoking habits varied significantly between subjects with and without chronic bronchitis in both sexes and in the total sample. 
Table 4. - Adjusted odds ratios (OR), 95\% confidence intervals $(95 \% \mathrm{Cl})$ and p-values for the effect of smoking habits, respiratory infection before the age of $5 \mathrm{yrs}$, occupational exposure and socioeconomic status on chronic bronchitis

\begin{tabular}{|c|c|c|c|c|}
\hline & \multicolumn{2}{|c|}{ Males } & \multicolumn{2}{|c|}{ Females } \\
\hline & OR & $95 \% \mathrm{CI}$ & OR & $95 \% \mathrm{CI}$ \\
\hline \multicolumn{5}{|l|}{ Smoking habits $\#$} \\
\hline Past smoker & 1.38 & $0.84-2.26$ & 1.08 & $0.67-1.72$ \\
\hline Current smoker $1-14$ pack-yrs & $3.51 * * *$ & $2.31-5.32$ & $3.06^{* * *}$ & $2.13-4.40$ \\
\hline Current smoker $15-29$ pack-yrs & $6.32 * * *$ & $4.20-9.52$ & $5.02 * * *$ & $3.36-7.48$ \\
\hline Current smoker $30-44$ pack-yrs & $12.13^{* * *}$ & $7.57-19.46$ & $8.47^{* * *}$ & $4.89-14.65$ \\
\hline Current smoker $\geqslant 45$ pack-yrs & $17.32 * * *$ & $9.97-30.11$ & $10.63^{* * *}$ & $4.69-24.13$ \\
\hline \multicolumn{5}{|l|}{ Respiratory infection before the age of $5 \mathrm{yrs}$} \\
\hline Yes versus no & 0.90 & $0.57-1.41$ & 1.40 & $0.95-2.07$ \\
\hline Occupational exposure & & & & \\
\hline Yes versus no & $1.49 *$ & $1.12-1.98$ & $1.66^{* * *}$ & $1.26-2.18$ \\
\hline \multicolumn{5}{|l|}{ Socioeconomic status } \\
\hline Low versus high & $1.35^{*}$ & $1.01-1.81$ & 1.08 & $0.79-1.48$ \\
\hline
\end{tabular}

The ORs were calculated by a multilevel logistic regression model with random intercept at the level of the European Community Respiratory Health Survey (ECRHS) centre and all predictor variables as fixed effects. The ORs were also adjusted for the effect of the percentage of responders to questions on asthma and bronchitis in each ECRHS centre. ${ }^{\#}$ : versus nonsmokers; *: $\mathrm{p}<0.05$; ***: $\mathrm{p}<0.001 ; \mathrm{p}$-values for the main factors were determined using the Wald test.

have a different disease evolution and may not necessarily develop bronchial obstruction in the future. On the other hand, in the total sample, it was found that $4.3 \%$ of subjects who did not have chronic bronchitis did have bronchial obstruction: some of these could have isolated bronchial obstruction in the absence of chronic hypersecretion. This finding has already been highlighted in previous studies [17, 18] and requires further investigation. The ongoing new cycle of ECRHS will allow the authors to address this topic better.

The present study documents a widespread variation in chronic bronchitis among countries, with centres in Spain, Ireland and the USA showing the highest rates. Previous data are not always comparable because of imprecise and variable definitions of the disease. In a recent study, evaluating the performance of different respiratory symptom questionnaires in international comparisons of prevalence and risk factors, it was stated that small changes in the phrasing of a question can have a considerable effect on prevalence estimates [19]. The ECRHS study employed the same standardized questionnaire, validated in the different languages, and the same protocol for lung function tests was used.

Although over the past decades much effort has been devoted to decreasing per capita cigarette consumption, the presented data show that the percentage of smokers is still high in many countries. However, at least in some countries, namely the USA, UK, Australia, New Zealand and Sweden, the positive effect of intensive antismoking campaigns is reflected by the high percentage of past smokers. To the best of the authors' knowledge, this is the first study which incorporates homogeneously collected data on individual smoking habits across countries. The association between smoking habits and chronic bronchitis is well known, and the present study adds further evidence in this regard, showing a clear dose-response relationship, both with the increase in prevalence of chronic bronchitis and with the decrease in FEV1\% pred, consistent in all countries.

As far as the interaction between smoking and sex is concerned, in the young population the effect of smoking on chronic bronchitis was more pronounced in males than in females. Previous studies, considering losses in lung function and hospitalization as a results of chronic bronchitis, suggest that female smokers seem to be more susceptible to the effect of cigarette smoking [20]. However, in a recent meta-regression analysis, no difference in the effect of smoking habits on lung function was found between males and females [21].

Many other factors, besides smoking, are involved in chronic bronchitis. Evidence relating occupational environment to chronic bronchitis is extensive but conflicting, above all because of the complex, adverse interactions with smoking and other environmental agents [21]. The presented data underline the fact that occupational exposure has a significant, independent role in the development of chronic bronchitis. The relationship between socioeconomic status and chronic bronchitis has been established both in males and females [16, 22]. Using educational level as an index of socioeconomic status, a significant effect on chronic bronchitis only in males was observed. This difference could be explained by the simplistic index, not including income, used in the present study. Age was not found to be an independent predictor of chronic bronchitis in the young subjects, when adjusting for the other covariates. This suggests that when a positive association between age and chronic bronchitis is found in young adults, it is likely to reflect the effect of some time-cumulative exposure (like smoking) rather than an ageing effect.

Even if smoking is the strongest risk factor for chronic bronchitis, $17 \%$ of chronic bronchitic subjects never smoked and $35.6 \%$ of subjects without chronic bronchitis were smokers. Furthermore, when the ecological relationship between smoking and chronic 
bronchitis is considered, only $30 \%$ of the geographical variation in prevalence can be accounted for by smoking habits. At least part of this unexplained geographical variation could be attributed to other risk factors, such as indoor and outdoor pollution [23], for which unfortunately no data are available. There is also evidence that genetic factors, such as alpha-1-antitrypsin deficiency, and individual susceptibility play an important role in the development of the disease [24].

One potential problem in interpreting the presented results is that there was a large variation in response rates across centres. A low response rate may lead to considerable over- or underestimation of the actual prevalence, if participation in the survey is related to the presence of symptoms [25]. However, previous studies showed that the effect of nonresponse was negligible in the second stage of ECRHS [26, 27]. Since it is known that smokers are more likely to be nonresponders than nonsmokers [25], it is probable that the prevalence of chronic bronchitis and of current smoking in the centres with the highest nonresponse rates were slightly underestimated. When the analysis was repeated, excluding the centres with a response rate $<40 \%$, there was neither substantial change in the emerging geographic pattern of chronic bronchitis prevalence, nor in ecological correlation estimates. Moreover, in the risk assessment analysis, the model used allowed the authors to control for the potential bias attributable to nonresponse. A further limitation that should be taken into account when considering the prevalence estimates at national level is that the centres were not selected to be representative of their countries.

In conclusion, the present analysis has shown that chronic bronchitis is a substantial health problem even in young adults, in almost all countries with wide variation both across and within countries, which can only be partly explained by different patterns in smoking habits. Further research is needed in order to understand which factors, other than smoking, play a role in increasing the likelihood of developing chronic bronchitis and in explaining the geographical variation in prevalence. The proportion of current smokers among young adults is still impressively high in most countries. Overall, the presented results emphasize the need for further worldwide efforts, particularly antismoking campaigns, to improve the quality of prevention for all tobacco-related diseases.

Team members of the ECRHS-Study Group: W. Popp (Vienna, Austria); M. Abramson, J. Kutin (Melbourne, Australia); P. Vermeire, F. van Bastelaer (Antwerp South \& Antwerp Central, Belgium); J. Bousquet, J. Knani (Montpellier), F. Neukirch, R. Liard (Paris), I. Pin, C. Pison (Grenoble), A. Taytard (Bordeaux, France); H. Magnussen, D. Nowak (Hamburg), H.E. Wichmann, J. Heinrich (Erfurt, Germany); N. Papageorgiou, P. Avarlis, M. Gaga, C. Marossis (Athens, Greece); T. Gislason, D. Gislason (Reykjavik, Iceland); J. Prichard, S. Allwright, D. MacLeod (Dublin, Ireland); M. Bugiani, C. Bucca, C. Romano (Turin), R. de Marco, V. Lo Cascio, C. Campello (Verona), A. Marinoni,
I. Cerveri, L. Casali (Pavia, Italy); B. Rijcken, A. Kremer, (Groningen, Bergen-op-Zoom, Geleen, the Netherlands); J. Crane, S. Lewis, (Wellington, Christchurch, Hawkes Bay, New Zealand); A. Gulsvik, E. Omenaas (Bergen, Norway); J.A. Marques, J. Alves (Oporto, Portugal); J.M. Antò, J. Sunyer, F. Burgos, J. Castellsangué, J. Roca, J.B. Soriano, A. Tobìas (Barcelona), N. Muniozguren, J. Ramos Gonzàles, A. Capelastegui (Galdakao), J. Castillo, J. Rodriguez Portal (Seville), J. Martinez-Moratalla, E. Almar (Albacete), J. Maldonado Pérez, A. Pereira, J. Sànchez (Huelva), J. Quiros, I. Huerta, F. Pavo, (Oviedo, Spain); G. Boman, C. Janson, E. Bjornsson (Uppsala), L. Rosenhall, E. Norrman, B. Lundback (Umea), N. Lindholm, P. Plaschke (Goteborg, Sweden); U. Ackermann-Liebrich, N. Kunzli, A Perruchoud (Basel, Switzerland); M. Burr, J. Layzell (Caerphilly), R. Hall (Ipswich), B. Harrison (Norwich), J. Stark (Cambridge, UK); S. Buist, W. Vollmer, M. Osborne (Portland, USA).

Team members of the ECRHS Co-ordinating Centre (London): Project leader: P. Burney, S. Chinn, C. Luczynska, D. Jarvis, E. Lai.

Team members of the ECRHS Project Management Group: Project leader: P. Burney; S. Chinn, C. Luczynska, D. Jarvis (all London); P. Vermeire (Antwerp); H. Kesteloot (Leuven); J. Bousquet (Montpellier); D. Nowak (Hamburg); the late J. Prichard (Dublin); R. De Marco (Verona); B. Rijcken (Groningen); J.M. Anto (Barcelona); J. Alves (Oporto); G. Boman (Uppsala); N. Nielsen (Copenhagen); P. Paoletti (Pisa).

\section{References}

1. Chen CJ, Mannino DM. Worldwide epidemiology of chronic obstructive pulmonary disease. Curr Opin Pulm Med 1999; 5: 93-99.

2. American Thoracic Society. Standards for the diagnosis and care of patients with chronic obstructive pulmonary disease. Am J Respir Crit Care Med 1995; 152: Suppl. 5, S77-S121.

3. Siafakas NM, Vermeire P, Pride NB, et al. Optimal assessment and management of chronic obstructive pulmonary disease (COPD). Eur Respir J 1995; 8: $1398-1420$.

4. Burney PG, Luczynska C, Chinn S, Jarvis D. The European Community Respiratory Health Survey. Eur Respir J 1994; 7: 954-960.

5. Medical Research Council. Respiratory symptoms questionnaire. London, The Council, 1976.

6. United Medical and Dental Schools of Guy's and St. Thomas's Hospitals, Department of Public Health Medicine. Protocol for the European Community Respiratory Health Survey, London, 1993.

7. American Thoracic Society. Standardization of spirometry. Am Rev Respir Dis 1979; 119: 831-838.

8. Viegi G, Pedreschi M, Pistelli F, et al. Prevalence of airway obstruction in a general population. Chest 2000; 117: Suppl. 2, 339s-345s.

9. Fleiss JP. The Design and Analysis of Clinical Experiments. New York, John Wiley and Sons, 1986; pp. 59-68.

10. Kotz S, Johnson NL. Encyclopedia of Statistical Sciences. Vol. 5. New York, John Wiley and Sons, 1985; pp. $214-217$. 
11. Goldstein H. Multilevel Statistical Models. London, Edward Arnold, 1995.

12. Rasbash J, Browne W, Goldstein H, et al. A User's Guide to MLwiN. Version 2.1. Multilevel Models Project. London, Institute of Education, University of London, 2000.

13. Renwick DS, Connolly MJ. Prevalence and treatment of chronic airways obstruction in adults over the age of 45. Thorax 1996; 51: $164-168$.

14. Montnemery $\mathrm{P}$, Adelroth $\mathrm{E}$, Heuman $\mathrm{K}$, et al. Prevalence of obstructive lung diseases and respiratory symptoms in southern Sweden. Respir Med 1998; 92: $1337-1345$

15. Isoaho R, Puolijoki H, Huhti E, Kivela SL, Laippala P, Tala E. Prevalence of chronic obstructive pulmonary disease in elderly Finns. Respir Med 1994; 88: $571-580$

16. Prescott E, Lange P, Vestbo J. Socioeconomic status, lung function and admission to hospital for COPD: results from the Copenhagen City Heart Study. Eur Respir J 1999; 13: 1109-1114.

17. Peat JK, Woolcock AJ, Cullen K. Decline of lung function and development of chronic airflow limitation: a longitudinal study of non-smokers and smokers in Busselton, Western Australia. Thorax 1990; 45: 32 - 37.

18. Krzyzanowski M, Jedrychowski W, Wysocki M. Factors associated with the change in ventilatory function and the development of chronic obstructive pulmonary disease in a 13-year follow-up of the Cracow Study. Risk of chronic obstructive pulmonary disease. Am Rev Respir Dis 1986; 134: 1011-1019.

19. Brogger JC, Bakke PS, Gulsvik A. Comparison of respiratory symptoms questionnaires. Int $J$ Tuberc Lung Dis 2000; 4: 83-90.
20. Prescott E, Bjerg AM, Andersen PK, Lange P, Vestbo J. Gender difference in smoking effects on lung function and risk of hospitalization for COPD: results from a Danish longitudinal population study. Eur Respir J 1997; 10: 822-827.

21. Vollmer WM, Enright PL, Pedula KL, et al. Race and gender differences in the effects of smoking on lung function. Chest 2000; 117: 764-772.

22. Kogevinas M, Anto JM, Tobias A, et al. Respiratory symptoms, lung function and use of health services among unemployed young adults in Spain. Spanish Group of the European Community Respiratory Health Survey. Eur Respir J 1998; 11: 1363 1368.

23. Hasford B, Fruhmann G. Air pollution and daily admissions for chronic obstructive pulmonary disease in six European cities: results from the APHEA project. Air Pollution and Health, a European Approach. Eur Respir J 1998; 11: 992-993.

24. Silverman EK, Chapman HA, Drazen JM, et al. Genetic epidemiology of severe, early-onset chronic obstructive pulmonary disease. Am J Respir Crit Care Med 1998; 157: 1770 - 1778

25. de Marco R, Verlato G, Zanolin E, Bugiani M, Drane JW. Nonresponse bias in EC Respiratory Health Survey in Italy. Eur Respir J 1994; 7: $2139-2145$.

26. Janson C, Chinn S, Jarvis D, Burney P. Physiciandiagnosed asthma and drug utilization in the European Community Respiratory Health Survey. Eur Respir J 1997; 10: 1795-1802.

27. Burney P, Malmberg E, Chinn S, Jarvis D, Luczynska $\mathrm{C}$, Lai E. The distribution of total and specific serum IgE in the European Community Respiratory Health Survey. J Allergy Clin Immunol 1997; 99: 314-322. 